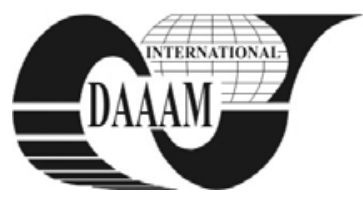

Annals of DAAAM for 2011 \& Proceedings of the 22nd International DAAAM Symposium, Volume 22, No. 1, ISSN 1726-9679 ISBN 978-3-901509-83-4, Editor B. Katalinic, Published by DAAAM International, Vienna, Austria, EU, 2011 Make Harmony between Technology and Nature, and Your Mind will Fly Free as a Bird

\title{
SMART CITY MANAGEMENT AND HOLONIC MANUFACTURING CONCEPT
}

\author{
BAKOS, L[evente] - A[ttila]
}

\begin{abstract}
The Holonic Manufacturing concept, as one of the most promising modern manufacturing concept, proved its efficiency in the real industrial environment. The paper tries to show a possible application of the holonic concept in public administration and city management. The new trend in developing "smart" or" intelligent" cities can certainly use some of the results of the HMS model.
\end{abstract}

Key words: holonic manufacturing systems, smart cities, city management, virtual enterprise, risk management

\section{INTRODUCTION}

According to the United Nations more than $50 \%$ of the world's population lives in urban areas, and it is expected to rise to $70 \%$ until the middle of this century. The cities must deal with this trend, and meanwhile they have to remain safe, attractive, environmental friendly. Many researchers are working on innovative solutions to help create liveable, sustainable and intelligently connected cities. Similarly to manufacturing companies different systems must integrate and work together in cities. Thus, within certain conditions and limits, the city can be considered as a virtual enterprise, which has to fulfil all the expected functions.

\section{SMART CITIES}

A city can be defined as 'smart' when investments fuel sustainable economic development and a high quality of life. This means a wise management of natural resources and participatory governance. The steady influx of the world's population into urban areas encourages city planners to invest in smart technologies-a move that result in saving money, time and, in some cases, lives. Urban performance currently depends not only on the city's financial resources, but also on the availability and quality of knowledge communication and social infrastructure. The intellectual and social capital is decisive for urban competitiveness, and it is encouraged by the European Union regional development policy, too. Urban planners, real estate developers, utility companies, infrastructure providers, telecommunications firms, IT developers and service providers are working together today to build the cities of tomorrow.

Nevertheless, we must observe that the growth of urban areas generates important risks. In this paper we deal only with the risks generated by ineffective communication. The major communication risks can be handled by advanced information technology, analytic and system thinking, which stimulate a thriving, knowledge-driven economy. The mainstream in handling such complex adaptive systems is the distributed system approach, including the revolutionary achievements of information technology, such is the cloud-computing. Cities can improve their current service capacities by making their core systems smarter: transport, public safety, government services, education and health. This is possible by means of major leading companies such as IMB, Amazon, CISCO or Philips.

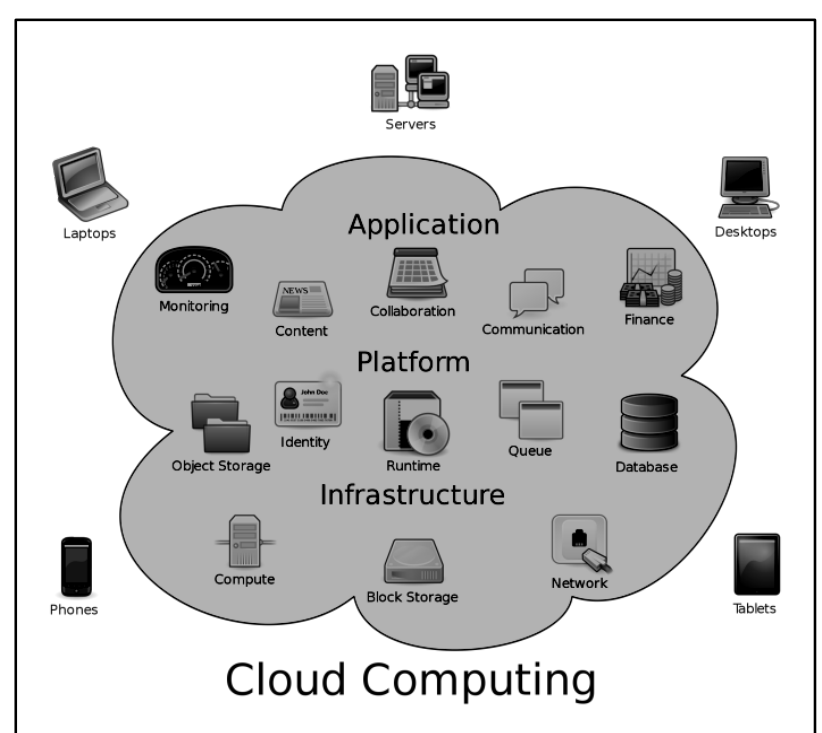

Fig. 1.Cloud computing $(* * *, 2011)$

We have to mention that large-scale communication need is risk in itself. It could be an important challenge for the public administration to avoid the emerging monopole situation of certain major companies. The public utilities are seen to have the greatest exposure, the related sensitive information is potentially dangerous if falls into wrong hands.

\section{LESSONS FROM THE HMS MODEL}

The Holonic Manufacturing Systems (HMS) is one of the six major projects of Intelligent Manufacturing Systems (IMS) program resulting from a feasibility study conducted at the beginning of the 1990's. Based on the term 'holon' (an entity which is a "whole" and a "part" at the same time) the model is inspired from living organisms and social organizations, and is still one of the most promising models in modern manufacturing. The model has already proved its efficiency under the present dynamically changing market conditions and it manages extremely well the rapidly changing technologies.

Originally the holonic manufacturing concept originally was developed mostly for scheduling purposes or to handle disturbances at job-shop level. Let us mention only the most cited holonic reference architecture, the PROSA (Brussels et al, 1998). Later the researchers developed solutions for all enterprise levels. Recent researches exceed the enterprise internal environment and concentrate on activities like supply chain management (Banyai, 2009), virtual enterprises or emergent enterprise alliances (Ulieru, 2004).

The aim of this paper is to show that the holonic concept can be applied even on a larger scale: urban conglomerations or the large scale human (non industrial) activities. As it was stated above, the holonic concept has its origins in the 
examination of the behaviour of social and organic structures. The outcoming rules were put into manufacturing environments, such as job-shops or entire enterprises. The developed architectures, communication protocols are based on strong mathematical and computational methods, and now are operational in industrial or economic environments. Having their main pattern similar to social or natural organizations, these communication protocols can be used to handle other complex systems, in our case an entire city.

The flexibility, disturbance handling efficiency and predictive behaviour of the HMS concept, make them suitable for problem solving in city management. Let us give some examples where a similar problem handling is obvious. For instance the holonic system used by Rockwell Automation for the US Navy to control chilled water system on its ships can be certainly used, on a larger scale to solve the water supply or the heating system of the cities. The developed system may distribute holonic controls over many nodes, and holons are placed close to the equipment they direct. The holons must then determine if there is a break in the system and reroute the water around the break. Other similarities may be found between the holonic models developed for AGV-s or other transport problems inside the enterprise with traffic monitoring the cities. Managing peak situations in traffic or in case of special events (such as the Olympics or FIFA World Cup, mega-concerts, flood, etc.) can be handled by the algorithms developed for the Holonic Manufacturing Systems.

\section{A CASE STUDY}

The focus of our research is Tîrgu Mures, a middle sized (150.000 inhabitants) town in Romania. The town is large enough to be a pilot city, not only for our research, but for some major developers, as well. IBM already signed a partnership agreement with the municipality. In order to develop business solutions for public administrations the partnership agreement with IBM led to other partnership agreements, such as the one between Sapientia University and the municipality. Recently, another world-wide solution developer, the lighting division of Philips presented an offer to the city management. Their solution, Philips CityTouch, is already functional in Prague, and it is a sophisticated cloud-based CMS for tele-managing street lights in urban areas. It is a flexible lighting management, which provides light, when and where it is required in a proper amount using a single integrative interface.

The first steps in becoming a 'smart' city were made few years ago, when an integrated emergency response unit became operational in the city. Probably it is one of the best in EasternEurope, and it is the pilot unit for the Romanian emergency network. The developed system handles in matter of seconds all emergency calls and directs the right operative team at the right location. During this project, for first time in Romania, it was possible to efficiently coordinate the activity of all the structures which may act in case of emergency. This means that the operatives of the police, fire department, ambulance and local authorities are working and acting at the same headquarters. Recently, the emergency response unit enlarged its activity with perimeter surveillance, traffic control, health monitoring, regional helicopter rescue.

Our research topic is to develop a holonic system, including a communicational protocol, which can handle the existing and the prospective city management systems. The already operational emergency system and the prospective business solutions for public administration must work together. We created the frame of a virtual enterprise, a holonic system, which can integrate all the major subsystems, assuring the safety and cost effective functioning. The main idea of the emerging system is shown in Fig.2.

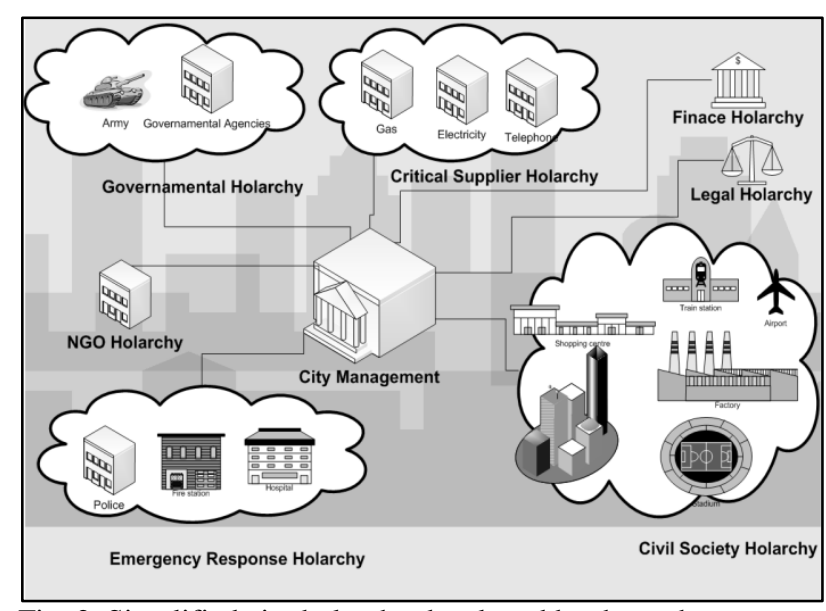

Fig. 2. Simplified city holarchy developed by the author

\section{CONCLUSION, FUTURE WORK}

The HMS model, as we emphasized above, can be a solution for the key problems of the developing cities. Our research aims to support the our city management to design a smart city, in which it the main idea is to do more with less. We suggest a holonic systemic approach which implies an interconnected complex of functionally related components. We developed a local holonic system to simulate how the related components may work together, and the next step is to finalize the holarchies and the internal decisional standards.

In the future work we intend to develop a detailed communication protocol, we are aware of that the effectiveness of each component relies on how it fits into the whole, and the effectiveness of the whole depends on the way each component functions.

\section{ACKNOWLEDGEMENTS}

The project is supported by the Municipality of Tîrgu Muşe Romania, and Sapientia Hungarian University of Transylvania.

\section{REFERENCES}

Banyai, A. (2009). Just-In-Time Supply Within The Frames Of Virtual Enterprises, Annals of DAAAM for 2009 \& Proceedings of the 20th International DAAAM Symposium, Volume 20, No. 1, ISSN 1726-9679, ISBN 978-3-90150970-4, Editor B. Katalinic, Published by DAAAM International, Vienna, Austria, EU

Brussel, H., Wyns, J., Valckenaers, P., Bongaerts L., Peeters P. (1998) Reference architecture for holonic manufacturing systems: PROSA. Computers in Industry 373

Ulieru,M. \& Unland, R. (2004). Enabling Technologies For The Creation And Restructuring Process Of Emergent Enterprise Alliances, International Journal of Information Technology \& Decision Making Vol. 3, No. 1 33-60, World Scientific Publishing Company

*** (2007) World Urbanization Prospects: The 2007 Revision, United Nations, Available from http://www.un.org, Accessed on 2011.10.08

*** (2009) http://www.ibm.com -A vision of smarter cities., IBM Institute for Business Value, Accessed on 2011.10.08

***(2010) http://www.cio.gov -State of Public Sector Cloud Computing, Accessed on 2011.10.08

*** (2011) http://www.lighting.philips.com- Citytouch. Bring city lighting to life Accessed on 2011.10.08 